\title{
EFFECT OF DUST AND FUME EXPOSURE ON LUNG FUNCTION AMONG FOOD PROCESSING WORKERS IN SEMARANG, CENTRAL JAVA
}

\section{Dea Amarilisa Adespin, Hari Peni Julianti, Aras Utami, Dodik Pramono, Diah Rahayu Wulandari}

Faculty of Public Health, Universitas Diponegoro

\begin{abstract}
Background: Workers in many industrial areas are exposed to various inhalable agents including dust, gases, fumes, and organic solvents. These agents may cause several respiratory diseases. This study aimed to examine the effect of dust and fume exposure on lung function among food processing workers in Semarang, Central Java.

Subjects and Method: This was a cross sectional study conducted at a food processing factory in Semarang, Central Java. A total of 264 workers was selected for this study. The dependent variable was lung function. The independent variables were dust and fume exposure. Data on dust and fume exposures were obtained through interview using structured questionnaire and observation. Lung function was measured by spirometer. The data were analyzed by Chi-square.

Results: A total of $12.9 \%$ workers exposed to dust and 9.8\% exposed to fume. $22.3 \%$ workers had lung function disorder. Most lung disorders were mild restriction. Dust and fume exposures were positively associated with lung function disorder, and they were statistically significant.

Conclusion: Dust and fume exposures are positively associated with lung function disorder.
\end{abstract}

Keywords: dust, fume, exposure, lung function, worker

\section{Correspondence:}

Dea Amarilisa Adespin. Faculty of Public Health, Universitas Diponegoro, Semarang, Central Java. Email: dea.amarilisa@gmail.com. Mobile: 085743535757. 